\title{
new protocol for subjective assessment of neurocognitive function in paediatrics
}

\author{
Somaya El-SayedHadhoud MD ${ }^{1}$, Ahlam Abdel Salam Nabieh El-Adawy MD², \\ AbeerAbdElmonem Ahmed MD $^{1}$, Mona Abo-Alkasem Mahmoud MS ${ }^{1}$ \\ ${ }^{1}$ Pediatric Department, Sohag University Hospital, Sohag University, Sohag, Egypt \\ ${ }^{2}$ Phoniatrics, ENT Department, Sohag University, Sohag, Egypt
}

\begin{abstract}
Introduction and aim of work Neurocognitive testing, also known as neuropsychological testing, is a performance-based method to assess cognitive functioning by comprehensive evaluation of the patient's cognitive status by specific neurologic domains ( attention, memory , judgement ,evaluation, reasoning ,computation, problem solving , decision making, comprehension and production of language(Butler et al,2013). There are many protocols for neurocognitive assessment in paediatrics; we developed new protocol for evaluation of neurocognitive function of paediatric group suitable for healthy and unhealthy children in Egyptian children. The validity and specificity were studied by application the protocol into two groups: one normal kids and the others with NHL treated with intrathecal methotrexate(Dietrich,2010)..
\end{abstract}

Patients and methods: the first step is to design the protocol for subjective evaluation of neurocognitive function. Second step is applying the protocol on two groups. The group one included 25 NHL(Non Hodgkin Lymphoma) treated children and the group two includes 10 children as controls. The third step to correlate the results with the result of standered test (StandfordBinet test 4 th editions).

Result The design protocol is effective to evaluate the neurocognitive function and assess the minimal change as it seen obvious in the difference between the groups and the correlation with the result of StandfordBinet test.

\section{Introduction}

Cognition is the set of all mental abilities and processes related to knowledge. Human cognition is conscious and unconscious, concrete or abstract, as well as intuitive and conceptual .Cognitive processes use existing knowledge and generate new knowledge (Anderson and John, 2014).

Neurocognitive testing is used to examine the cognitive consequences of brain damage, brain disease, effect of systemic disease or malignancy,effect of certain medication or modes of therapy and mental illness (Anderson and John, 2014).

\section{Aim of the work}

In order to design general protocolfor evaluation of neurocognitive function suitable to assess the neurocognitive function in paediatrics groups .

\section{Patients and methods:}

1) First step to design protocol for subjective evaluation of neurocognitive function, the design of the protocol passed through these steps:

a-It was established by one paediatrician.

b-Reviewed and revised by the paediatricians of sohag university pediatrics department and phoniatricans of sohag university phoniastrics unit .

c-To detect its sensitivity and specifity it was applied in 25 patients who receive intrathecal chemotherapy in treatment of Non Hodgkin Lymphoma and 10 healthy children.

d-Statistics :the results were analysed by comparing results with result of Stanford Binet test to assess significance of protocol.

2)second step applying the protocol on two groups :the group one included 25( Non 
SOHAG MEDICAL JOURNAL Developed new protocol for subjective assessment of neurocognitive

Hodgkin Lymphoma ) treated children, the group two 10 healthy children to test validity and specifity of the protocol. 3)third step correlate the result of protocol with result of StandFordBinet test (objective evaluation)

\section{Result}

I-After application our subjective evaluation by protocol, we assessed:

a-appearance b-motor behaviour c-voice, speech, language .

d-interaction with examiner e-mood and affect

f-cognitive function (attention,memory,orientation) see appendix 1

II-we assess

the 3 previous cognitive function1-All children showed good orientation to person, place and time.

2- In memory we covered( recent, immediate and remote memory) there is difference between results between cases and controls but the difference is not significantby subjective evaluation by the protocol table 1 ( $p$ value .952)

Table 1 The results of memory study in cases and controls

\begin{tabular}{|l|r|r|}
\hline & mean & SD \\
\hline cases & $\mathbf{7 9}$ & $+/-13.2$ \\
\hline controls & $\mathbf{8 2 . 5}$ & $+/-22.9$ \\
\hline
\end{tabular}

3- In attention there is difference between cases and controls but it is not significantby subjective evaluation by the protocol table 2 ( $\mathrm{p}$ value $=.971$ )

Table 2 The results of attention study in cases and controls

\begin{tabular}{|l|r|c|}
\hline & mean & SD \\
\hline cases & 77 & $+/-12.8$ \\
\hline controls & 85 & $+/-23.9$ \\
\hline
\end{tabular}

III- Is there correlation in results between subjective evaluation by protocol and objective evaluation by StandfordBinet test in attention and memory to detect reliability of protocol.

Table 3 Comparison between cases and control in attention and memory by standfordBinet (objective)

There is no significant difference between cases and controls in attention and memory.

\begin{tabular}{|l|l|l|l|}
\hline variable & cases & controls & P value \\
\hline attention & $\mathbf{2 . 2 7} \pm \mathbf{1 . 0 8}$ & $\mathbf{2 . 0 0} \pm \mathbf{0 . 9 4}$ & $\mathbf{0 . 4 9 6}(\mathbf{N S})$ \\
\hline $\begin{array}{l}\text { Short term } \\
\text { memory }\end{array}$ & $\mathbf{1 0 5 . 6 8} \pm \mathbf{2 2 . 1 7}$ & $\mathbf{1 1 4 . 7 0} \pm \mathbf{1 8}$ & $\mathbf{0 . 2 6}(\mathbf{N S})$ \\
\hline
\end{tabular}

The designedprotocol is valid and specific in assessment of some neurocognitive function as the same results obtained from objective evaluation by test and subjective evaluation by protocol 


\section{Discussion}

we choosed NHL treated childen as this tumor is the $3^{\text {rd }}$ in childhood malignancyand because childhood cancer survivors frequently experience longlasting consequences of chemotherapy on health outcomes. These consequences affect mental health, school performance, job success, and are associated with poor quality of life.(Gazdzinski et al., 2012 )we need to cover attention, ,memory, verbal comprehension, visuospatial skills ,visuomotor functioning, reading ,mathematical skills and executive functions (Buizer et al,2009) we choose attention and memory in protocol because their fundamental role in neurocognition and participation in many mental skills(Buizer et al,2009)

The application of this protocolis much easier than specific intelligence test, as it needs only clinician but StandFord Binet test needs qualified technician and the results of protocol is correlated with test.. also application of protocol is less time consuming and needs less devices and costs less money.

The protocol is effective in assessing the defects in some neurocognitive domains in children.

Appendix 1

New protocol for subjective assessment of neurocognitive function in paediatrics

\section{Mental status examination}

1-appearanceHeightWeightNutritional statusPersonal hygiene (compared to family)

2-Motor behaviour

-abnormal movements yes noIf yes what is the abnormality

-General level of physical activity according to age(Normal ,hyperkinesia,hypokinesia)

-Gross and fine motor coordination

Gross (ask child to arrange some books above each other)Fine(ask child to write or draw)

3-voiceSpeechLanguage

4-interaction with the examiner

-eye contact (normal-starringunfocused-averted)

-cooperative (resistant-shy-aggressivefearful)

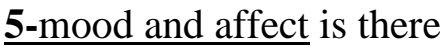

Anxiety depression Tension elevation of mood apathy non of above

6-congnitive functions

Attention Orientationmemory

Attention

To study attention in quasi-objective manner,we transform answer of children into percent according to wrong and right answers, this is score we use

Table 18 attention score

\begin{tabular}{|c|c|}
\hline score & Percent of right answers \\
\hline \hline 1 & $25 \%$ \\
\hline 2 & $50 \%$ \\
\hline 3 & $75 \%$ \\
\hline 4 & $100 \%$ \\
\hline
\end{tabular}


1-listento the following letters and in between I will say numbers when you listen to a number say yes

evaluation Number of error

$$
\text { (3 } 8 \text { ح } 9 \text { ح } 9 \text { ج ج هـ } 5 \text { ب } 3 \text { س ز } 0 \text { ص }
$$

2-listen to the following numbers and inbetween I will say letters when you listen to letter say yes

$$
995 \text { د } 6363 \text { ح } 955
$$

EvaluationNumber of errors

OrientationAsk the following questions:

Time

What is the day of the week? What is the date? what is the season?How long have we been talking?

Place

What is this placeHow did you get here? Is this place from your home?

\section{Person}

Tell me your name ?Who am i? what is my job? Why you come to see me?

what is the name of your school and in what grade you are?

Evaluation

number of accurate answers

memory

To study memory in quasi-objective manner,we transform answer of children into percent according to wrong and right answers .

Table 19 memoy score

\begin{tabular}{|c|c|}
\hline score & Percent of right answers \\
\hline \hline 1 & $25 \%$ \\
\hline 2 & $50 \%$ \\
\hline 3 & $75 \%$ \\
\hline 4 & $100 \%$ \\
\hline
\end{tabular}

recent memory

I will tell you 3 things to remember(name (first and last),address of 3words,color)

And ask him to repeat after few minutes

Evaluation, Accurate ,Need help cant repeat any ,Refused

(ask child to keep things in mind)

Immediate memory

Listen to me and repeat and record the last accurate repetition

834296421985213935396

Evaluation

Unable ,Refused, The ability to remember

Now tell me the previous 3 things

Remote memory

What is your address? What is your telephone number? Where were you born?

What is date of your birthday? what are your mother ,father ,siblings names? 


\section{References}

1. Anderson, John R (2004).Cognitive psychology and its implications $\left(6^{\text {th }}\right.$ ed.). Worth Publishers. 519. ISBN 9780-7167-0110-1.

2. Buizer AI, de Sonneville LM, Veerman A (2009). Effects of chemotherapy on neurocognitive function in children with acute lymphoblastic leukemia: A critical review of the literature. Pediatr Blood Cancer 52:447-54.

3. Butler RW, Fairclough DL, Katz ER (2013). Intellectual functioning and multi-dimensional attentional processes in long-term survivors of a central nervous system related pediatric malignancy. Life Sci 93(17):611-6.

4. Carlson, Neil R (2010). Psychology: the science of behavior. Boston, Mass: Allyn\& Bacon. ISBN 0-205-68557-9. OCLC 268547522.

5. Copeland DR, Moore BD, Francis DJ, et al.2000Neuropsychologic effects of chemotherapy on children with cancer: a longitudinal study. J ClinOncol. ;14:28262835.
6. Dietrich (2010). Chemotherapy associated central nervous system damage. AdvExp Med Biol. 678:77-85.

7. Gangjee A, Jain HD, Kurup S (2007).Recent advances in classical and non-classical antifolates as antitumor and antiopportunistic infection agents: part I. Anticancer Agents Med Chem 7(5):524-42.

8. Gazdzinski LM, Cormier K, Lu FG, Lerch JP, Wong CS, Nieman BJ (2012). Radiation-induced alterations in mouse brain development characterized by magnetic resonance imaging. International Journal of Radiation Oncology, Biology, Physics. 84(5):e631-638.

9. Kevin R. Krull, Raja B Khan, Kirsten K. Ness, DavonnaLedet, Liang Zhu, Ching-Hon Pui, Scott C. Howard, Deo Kumar Srivastava, Noah D. Sabin, Melissa M. Hudson, and E. Brannon Morris 2011ped blood cancer 57(7):1191-119 